nhiễm độc giáp, có những thay đổi về ngoại hình, tâm lý, ảnh hưởng đến thể chất, cảm xúc, khả năng học tập cũng như mối quan hệ với bạn bè và xã hội. Mặt khác, Basedow là một bệnh lý tự miễn, có khuynh hướng mạn tính và hay tái phát, trẻ Basedow phải uống thuốc thường xuyên và tái khám định kỳ gây ảnh hưởng nhiều đến CLS của trẻ, khiến điểm CLS của trẻ Basedow thấp hơn nhiều so với trẻ khỏe mạnh.

\section{KẾT LUÂ̂N}

Điểm chất lượng sống do trẻ mắc Basedow báo cáo thấp nhất ở lĩnh vực cảm xúc và có sự khác biệt giữa điểm CLS do trẻ và bố/me trẻ báo cáo trong lĩnh vực cảm xúc và học tập. Điểm CLS của trẻ mắc Basedow báo cáo ở nhóm tuổi 8-12 tuổi cao hơn nhóm tuổi 13-18 tuổi. Chất lượng sống liên quan đến sức khỏe ở trẻ mắc Basedow bị suy giảm so với trẻ khỏe mạnh cùng độ tuổi ở phần lớn các lĩnh vực, đặc biệt trong lính vực thể chất, cảm xúc, học tập và CLS tổng quát.
TÀI LIẸU THAM KHẢO

1. Nguyễn Thị Thanh Mai, Trân Thị Nết, Vũ Thương Huyên (2017). Khảo sát chất lượng cuộc sông liên quan sức khỏe ở trẻ em khỏe mạnh bằng thang PedsQL TM4.0 generic core scale, phiên bản Việt Nam. Tạp chí Y học Thực hành: 1045(6), 181-183.

2. Minamitani $K$, Sato $H$, Ohye $H$, et al (2017). Guidelines for the treatment of childhood-onset Graves' disease in Japan. Clinical Pediatric Endocrinology, 26(2): 29-62.

3. Varni J.W, Seid M, Kurtin P.S (2001). PedsQL ${ }^{T M}$ 4.0: reliability and validity of the Pediatric Quality of Life Inventory ${ }^{\mathrm{TM}}$ version 4.0 generic core scales in healthy and patient populations. Medical Care, 39(8): 800-812.

4. Lane L.C, Rankin J., Cheetham T. (2021). A survey of the young person's experience of Graves' disease and its management. Clinical Endocrinology, 94(2): 330-340.

5. Riguetto C.M, Neto A.M, Tambascia M.A et al (2018). The relationship between quality of life, cognition, and thyroid status in Graves' disease. Endocrine, 63(1): 87-93.

\title{
ĐÁNH GIÁ THỰC TRANG SỬ DUUNG THUỐC TRÊN BÊNHH NHÂN NGOẠI TRÚ CAO TUỔI BẰNG CÔNG CU STOPP TẠI BỆNH VIỆN TRƯỜNG ĐẠI HỌC Y KHOA VINH
}

\section{TÓM TÁ́T}

Mục tiêu: Đánh giá thực trạng đơn thuốc ngoại trú trển bệnh nhân cao tuổi bằng công cu STOPP và khảo sát một số yếu tố liên quan đến chỉ số PIM tại Bênh viên Trường Đai họ $Y$ khoa Vinh. Phương pháp nghiên cứu: Nighiển cứu tiến cứu mô tả cắt ngang, tài liệu nghiên cứu là đơn thuốc, bệnh án ngoại trú của bệnh nhân từ 60 tuổi trở lên tại khoa khám Bênh viên Trường Đai hoc $\mathrm{Y}$ khoa Vinh. Kết quả: Tỷ lệ gặp thuốc có khả năng không thích hợp theo STOPP 2014 trên đơn thuốc ngoai trú trong nghiên cứu là 18,35\%, trong đó ghi nhận được 21 loại PIM, hay gặp nhất là Aspirin ở bệnh nhân có tiền sử loét dạ dày tá tràng không dùng kèm PPI (20,34\%), các sulphonylurea có thời gian tác dụng dài như glibenclamid, glimepirid (13,65\%), PPI điều trị viêm loét dạ dày tá tràng không biến chứng hoặc viêm trợt thực quản khi dùng liều đầy đủ $>8$ tuần $(11,86 \%)$. Các yếu tố làm tăng khả năng gặp PIM theo STOPP 2014 gồm đa dược học OR=2,308 (CI95\%=1,130-

${ }^{1}$ Đại học Y khoa Vinh

Chịu trách nhiệm chính: Nguyễn Văn Tuấn

Email: tuanminh1975@gmail.com

Ngày nhận bài: 17.5.2021

Ngày phản biên khoa hoc: 30.6.2021

Ngày duyệt bài: 16.7.2021

\section{Nguyễn Văn Tuấn ${ }^{1}$, Trần Thị Anh Tho ${ }^{1}$}

$4,711, p=0,022)$, bệnh hệ tiêu hóa $O R=2,694$ $(\mathrm{CI} 95 \%=1,353-5,364, \mathrm{p}=0,005)$ và bệnh hệ tuần hoàn $\mathrm{OR}=2,828 \quad(\mathrm{CI} 95 \%=1,287-6,215, \mathrm{p}=0,010)$. Trong đó bệnh tim mạch là yếu tố có ảnh hưởng mạnh nhất đến khả năng gặp PIM theo STOPP 2014, nhóm bệnh nhân có bệnh tim mạch có nguy cơ gặp PIM cao gấp 2,8 lần so với nhóm không có bệnh tim mạch. Kết luận: Nghiên cứu cho thấy tỷ lệ kê đơn thuốc có khả năng không thích hợp (PIM) là 18,35\%. Hạn chế kê nhiều thuốc trên bệnh nhân cao tuối, đặc biệt từ 5 thuốc trở lên do tăng khả năng gặp PIM. Bệnh nhân mắc bệnh tim mạch hoặc hệ tiêu hóa tăng khả năng găp PIM.

Tư khóa: Người cao tuổi, STOPP, PIM

\section{SUMMARY}

ASSESSING THE STATUS OF DRUG USE IN ELDERLY OUTPATIENTS USING THE STOPP TOOL AT VINH MEDICAL UNIVERSITY HOSPITAL

Objectives: To assess the status of outpatient prescriptions in elderly patients using the STOPP tool and to investigate some factors related to the PIM index at Vinh Medical University Hospital. Methods: A cross-sectional prospective study, the research materials are prescriptions, outpatient medical records of patients with aged 60 years and older at the medical examination department of Vinh Medical University Hospital. Results: The rate of encountering 
potentially inappropriate drugs according to STOPP 2014 on outpatient prescriptions in the study was $18.35 \%$, of which 21 types of PIM were recorded, the most common was using Aspirin in patients with a history of peptic ulcer without PPIs (20.34\%), sulphonylureas with long duration of action such as glibenclamide, glimepiride (13.65\%), PPI for treatment of uncomplicated peptic ulcer or ulcer oesophagitis at full dose $>8$ weeks $(11.86 \%)$. Factors that increase the likelihood of encountering PIM according to STOPP 2014 include multiple pharmacology $\mathrm{OR}=2,308$ $(\mathrm{CI} 95 \%=1,130-4.711, \mathrm{p}=0.022)$, digestive system disease $\mathrm{OR}=2.694(\mathrm{CI} 95 \%=1,353-5,364, \mathrm{p}=0.005)$ and circulatory disease $\mathrm{OR}=2,828 \quad(\mathrm{CI} 95 \%=1.287$ $6.215, p=0.010)$. In which cardiovascular disease is the factor that has the strongest influence on the likelihood of having PIM according to STOPP 2014, the group of patients with cardiovascular disease has a 2.8 times higher risk of PIM than the group without cardiovascular disease. Conclusion: The study indicated that the rate of potentially inappropriate prescription (PIM) was $18.35 \%$. Limit multidrug prescribing in elderly patients, especially 5 or more drugs due to the increased likelihood of PIM. Patients with cardiovascular or gastrointestinal disease are more likely to experience PIM.

Keywords: Elderly, STOPP, PIM

\section{I. ĐĂTT VẤN ĐỀ}

Khi tuổi càng cao, sức đề kháng càng giảm cùng với những thay đổi của cơ thể khiến cho người cao tuổi dễ mắc nhiều bệnh phối hợp do đó cần sử dụng nhiều thuốc cùng một lúc. Đa dược học và kê đơn không hợp lý (IP) là những yếu tố nguy cơ được biết đến đối với $A D R$ trên bệnh nhân $(B N)$ cao tuổi do thường gây ra các kết cục lâm sàng bất lợi, thậm chí tử vong. Điều đó đòi hỏi phương thức xác định thuốc có khả năng không thích hợp (PIM - Potentially Inappropriate Medications) để nâng cao chất lượng và an toàn trên đối tượng đặc biệt này. STOPP (Screening Tool of Older Persons' potentially inappropriate Prescriptions - Công cụ sàng lọc các chỉ định không hợp lý tiềm ẩn ở bệnh nhân cao tuổi) được nâng cấp lần thứ 2 vào năm 2014 để phát hiện các sai sót tiềm tàng trong việc kê đơn và các tác dụng bất lợi (ADE), những nguyên nhân gây ra tình trạng nhập viện cấp tính ở người lớn tuổi [8]. Đề tài được thực hiện tại Bệnh viện Trường Đại học Y khoa Vinh mục tiêu: Đánh giá thực trạng đớn thuốc ngoại trú trên bênh nhân cao tuổi bằng công cu STOPP và khảo sát một số yếu tố liên quan đến chi số PIM tại Bệnh viện Trường Đại học Y khoa Vinh.

\section{II. ĐỐI TƯỢNG VÀ PHƯƠNG PHÁP NGHIÊN CỨU 2.1. Đối tướng nghiên cứu}

- Tiêu chuẩn lựa chon: Là đơn thuốc ngoại trú, bệnh án ngoại trú điện tử của bệnh nhân cao tuổi đến khám và điều trị tại khoa khám bệnh, Bệnh viện Trường Đại học Y khoa Vinh trong tháng 01/2021.

- Tiêu chuẩn loại trừ: hồ sơ những bệnh nhân (BN) chỉ được kê đơn thuốc y học cố truyền, không ghi nhận đủ thông số cận lâm sàng cần thiết, không khai thác được tiền sử dùng PPI.

\subsection{Phương pháp ngiên cứu}

2.2.1. Thiết kế nghiên cứu: Nghiên cứu tiến cứu mô tả cắt ngang

\subsubsection{Phương pháp thu thập số liệu}

- Cách lấy mẫu: cỡ mẫu là cỡ mẫu thuận tiện, gồm toàn bộ hồ sơ bệnh nhân phù hợp với tiêu chí lựa chọn trong thời gian nghiên cứu

- Các bước nghiên cứu:

+ Bước 1: Thu thập số liệu trên bệnh án ngoại trú điện tử qua phần mểm kê đơn thuốc của bệnh viện và đơn thuốc được bác sỹ kê.

+ Bước 2: Phân tích đơn thuốc (gồm thuốc BHYT và thuốc kê bệnh nhân tự túc).

+ Bước 3: Đánh giá PIM

$\checkmark$ Đơn thuốc đầy đủ thông tin để đánh giá PIM (a)

$\checkmark$ Đơn thuốc chưa đầy đủ thông tin để đánh giá PIM:

->Với PIM cần khai thác tình trang bênh lý: căn cứ vào chẩn đoán đơn ngoại trú/ kết quả cận lâm sàng của bệnh nhân: Các thông số creatinin máu, kali máu, natri máu căn cứ vào xét nghiệm hóa sinh máu. Để đánh giá PIM (b)

->Với PIM cần khai thác thông tin về thời gian sử dụng thuốc trích xuất dữ liệu bệnh sử của $\mathrm{BN}$ theo khoảng thời gian cần đánh giá tính từ thời điểm nghiên cứu, tham khảo đơn thuốc cũ, phỏng vấn bệnh nhân về tiền sử dùng thuốc. Đánh giá PIM (c)

Tổng số đơn gặp PIM $=a+b+c$

Tiêu chuẩn đánh giá: - Đánh giá tương tác thuốc bằng công cụ medscape.com và Stock's ley drug interection. Chỉ ghi nhận cặp tương tác từ mức độ cảnh báo trở lên.

- Đánh giá liều PPI trong điều trị viêm loét da dày tá tràng và viêm trợt thực quản theo Dược thư quốc gia Việt Nam 2015:

+ Omeprazole: 20 mg một lần/ ngày

+ Esomeprazol: 20mg một lần/ ngày

+ Lansoprazole: 30 mg một lần/ ngày

+ Pantoprazole: 40 mg một lần/ ngày

+ Rabeprazole; 20 mg một lần/ ngàY

2.3. Xử lý số liệu. Số liệu được xử lý bằng phần mềm SPSS 20.0, phân tích tương quan bằng phương pháp hồi quy logistic. Ảnh hưởng của các yễu tố có ý nghĩa thống kê khi $p<0,05$. 


\section{KẾT QUẢ NGHIÊN CỨU}

3.1. Đặc điểm bệnh nhân trong nghiên cứu. Trong thời gian nghiên cứu có $278 \mathrm{BN}$ gồm 198 nam $(71,2 \%)$ và 80 nữ $(28,8 \%)$, tuổi trung bình 70,28 $\pm 8,13$ (từ 60-95 tuổi). Phân loại nhóm tuổi theo WHO cho thấy có $74,1 \%$ số bệnh nhân tuổi từ 60-74, có 69 bệnh nhân tuổi từ 75-89 $(24,8 \%)$, chỉ có 3 bệnh nhân trên 90 tuổi $(1,1 \%)$

Đặc điểm bệnh lý trên bệnh nhân: Đa số bệnh nhân được chẩn đoán nhiều bệnh mắc kèm, số bệnh lý trung bình trên mội bệnh nhân là 3,29 $\pm 1,84$, dao động từ 1-9 bệnh, tỷ lệ bệnh nhân mắc 2 bệnh cao nhất $(23,38 \%)$, 3 bệnh $(20,14 \%)$. Trong đó các bênh lý được chẩn đoán nhiều nhất là bệnh hệ tiêu hóa $(74,10 \%)$, bệnh hệ tuần hoàn $(65,83 \%)$.

3.2. Đặc điểm sử dụng thuốc trên bệnh nhân của đối tượng nghiên cứu

3.2.1. Đặc điểm đơn thuốc. Tổng số thuốc được kê trong NC là 985 thuốc với số thuốc trung bình mỗi đơn là $3,54 \pm 1,78$, dao động từ 110 thuốc. Trong đó 194 đơn có từ 1-4 thuốc $(69,8 \%), 84$ đơn có 5 thuốc trở lên $(30,2 \%)$.

3.2.2. Đánh giá thực trạng kê đơn trên bệnh nhân cao tuổi theo STOPP 2014

Danh mục các thuốc được kê đơn ngoại trú nằm trong STOPP 2014. Công cụ STOPP có 80 mục để đánh giá tuy nhiên danh mục thuốc ngoại trú bệnh viện và kê đơn trên $B N$ trong nghiển cứu có 59 mục áp dụng được theo STOPP 2014. Số mục đủ tiêu chí để đánh giá được PIM là 47 mục chiếm tỷ lệ 58,75\%.

Tỷ lệ gặp PIM theo STOPP 2014 trên bệnh nhân nghiên cứu. Theo STOPP 2014 ghi nhận được 59 PIM trên 51 đơn thuốc (18,35\% ), dao động từ $1-2$ PIM, trong đó chỉ có 8 đơn gặp 2 PIM (2,88\%). Về phân bố đơn gặp PIM theo giới tính, nhóm tuổi cho thấy: tỷ lệ gặp PIM ở nữ cao hơn nam $(21,25 \%$ so với $17,17 \%)$, nhóm tuổi từ 90 trở lên cao hơn so với các nhóm tuổi khác (33,33\% so với $24,63 \%$ và $16,02 \%)$. Tỷ lệ gặp PIM ở đơn thuốc có từ 5 thuốc trở lên cao hơn so với đơn thuốc có từ 1 đến 4 thuốc (33,33\% so với $11,86 \%)$.

Phân bố PIM theo bệnh lý được chẩn đoán. Theo số bệnh lý được chẩn đoán: tỷ lệ PIM phân bố trên đơn không tăng đồng biến với số bệnh lý được chẩn đoán trên đơn. Nhóm bệnh nhân có từ 5 bệnh lý trở lên và bệnh nhân có 3 bệnh lý là nhóm có tỷ lệ gặp PIM cao nhất chiếm tỷ lệ $22,54 \%$ và $17,86 \%$.

Theo loại bệnh lý được chẩn đoán: nhóm bệnh nhân có bệnh hệ sinh dục-tiết niệu, hệ tuần hoàn, hệ tiêu hóa gặp PIM cao hơn các nhóm bệnh khác với tỷ lệ lần lượt là 20,89\%; $18,03 \%$ và $17,48 \%$.

Các loại PIM theo STOPP gặp trong nghiên cứu

Bảng 1. Các loại PIM theo STOPP trong nghiên cứu

\begin{tabular}{|c|c|c|c|c|}
\hline STT & Các PIM & $\begin{array}{l}\text { Lý do không phù hợp } \\
\text { theo STOPP } 2014\end{array}$ & $\mathbf{N}$ & $\%$ \\
\hline 1 & Thuốc chẹn beta kết hợp với verapamil hoặc diltiazem & Nguy cơ gây block Tim & 2 & 3,39 \\
\hline 2 & $\begin{array}{l}\text { Amiodarone là lựa chơn đầu tiên trong điêu trị loạn } \\
\text { nhịp ở bệnh nhẩn nhịp nhanh trên thất }\end{array}$ & $\begin{array}{l}\text { Nguy cơ cao gặp tác dụng } \\
\text { phụ nhiều hơn các thuốc } \\
\text { chen beta, digoxin }\end{array}$ & 1 & 1,69 \\
\hline 3 & $\begin{array}{c}\text { Thuốc lợi tiếu thiazide với bệnh nhân đang bị hạ kali } \\
\text { máu có ỹ nghĩa lâm sàng (hydroclorothiazid) }\end{array}$ & $\begin{array}{l}\text { Hạ kali máu, hạ natri máu, } \\
\text { tăng calci huyết và gout }\end{array}$ & 3 & 5,08 \\
\hline 4 & $\begin{array}{l}\text { Các thuốc ức chế ACE ở bệnh nhân tăng kali máu } \\
\text { (enalapril) }\end{array}$ & Tăng kali máu & 2 & 3,39 \\
\hline 5 & $\begin{array}{l}\text { Thuốc đối kháng aldosterone (spironolactone) dùng } \\
\text { đồng thời với các thuốc giữ kali (enalapril,quinapril) }\end{array}$ & Tăng kali máu & 2 & 3,39 \\
\hline 6 & $\begin{array}{c}\text { Aspirin ở bệnh nhân có tiên sử loét dạ dày tá tràng } \\
\text { không dùng kèm PPI }\end{array}$ & $\begin{array}{l}\text { Nguy cơ loét dạ dày - tá } \\
\text { tràng tái phát }\end{array}$ & 12 & 20,34 \\
\hline 7 & $\begin{array}{c}\text { Aspirin kết hợp với clopidogrel như là liệu pháp dự } \\
\text { phòng đột quy thứ phát }\end{array}$ & $\begin{array}{l}\text { Không có bằng chứng về lợi } \\
\text { ích tăng thêm }\end{array}$ & 1 & 1,69 \\
\hline 8 & $\begin{array}{c}\text { Aspirin kết hợp với kháng vitamin K ở bệnh nhân sơ } \\
\text { vữa động mạch mạn tính (acenocoumarol) }\end{array}$ & $\begin{array}{l}\text { Không có bằng chứng về lợi } \\
\text { ích tăng thêm }\end{array}$ & 2 & 3,39 \\
\hline 9 & $\begin{array}{l}\text { NSAID dùng đồng thời với các thuốc chống kết tập } \\
\text { tiểu câuu không phối hợp liệu pháp dự phòng bằng } \\
\text { PPI (clopidogrel) }\end{array}$ & $\begin{array}{c}\text { Tăng nguy cơ loét dạ dày - } \\
\text { tá tràng }\end{array}$ & 1 & 1,69 \\
\hline 10 & $\begin{array}{l}\text { PPI điều trị viêm loét da dày tá tràng không biến } \\
\text { chứng hoặc viêm trợt thực quản khi dùng liều }\end{array}$ & $\begin{array}{l}\text { Cân dừng sớm hơn hoặc } \\
\text { giảm liều được khuyến cáo }\end{array}$ & 7 & 11,86 \\
\hline
\end{tabular}




\begin{tabular}{|c|c|c|c|c|}
\hline & đầy đủ > 8 tuần & & & \\
\hline 11 & \begin{tabular}{|c|} 
Các thuốc dễ gây táo bón ở bệnh nhân táo bón \\
mạn (nhôm hydroxid)
\end{tabular} & $\begin{array}{c}\text { Nguy cơ làm nằng thêm tình } \\
\text { trạng táo bón }\end{array}$ & 1 & 1,69 \\
\hline 12 & $\begin{array}{l}\text { Thuốc an thần kinh chỉ định như là thuốc ngủ } \\
\text { (sulpiride) }\end{array}$ & $\begin{array}{c}\text { Nguy cơ lú lân, hội chứng } \\
\text { ngoại tháp }\end{array}$ & 1 & 1,69 \\
\hline 13 & $\begin{array}{l}\text { Corticosteroid đường toàn thân thay vì corticosteroid } \\
\text { dạng hít điêuu trị duy trì ở bệnh nhân COPD trung } \\
\text { bình hoặc nặng (methylprednisolon) }\end{array}$ & $\begin{array}{l}\text { Phơi nhiễm tác dụng KMM } \\
\text { của corticosteroid }\end{array}$ & 2 & 3,39 \\
\hline 14 & $\begin{array}{c}\text { NSAIDs ngoại trừ thuốc ức chế chọn looc COX-2 với } \\
\text { bệnh nhân có tiền sử loét da dày - tá tràng hoặc } \\
\text { xuất huyết tiêu hóa (naproxen) }\end{array}$ & $\begin{array}{l}\text { Nguy cơ loét dạ dày - tá } \\
\text { tràng tái phát }\end{array}$ & 3 & 5,08 \\
\hline 15 & $\begin{array}{l}\text { Corticosteroid trong điề trị viêm xương khớp } \\
\text { (methylprednisolone) }\end{array}$ & $\begin{array}{l}\text { Nguy cơ gặp tác dụng phụ } \\
\text { toàn thân nghiêm trong của } \\
\text { corticosteroid }\end{array}$ & 2 & 3,39 \\
\hline 16 & $\begin{array}{l}\text { Thuốc chẹn beta ở bệnh nhân đái tháo đường và thường } \\
\text { xuyên bị hạ đường huyết (metoprolol, bisoprolol) }\end{array}$ & $\begin{array}{l}\text { Nguy cơ che lấp các triệu } \\
\text { chứng của hạ đường huyết }\end{array}$ & 1 & 1,69 \\
\hline 17 & $\begin{array}{l}\text { Các sulphonylurea có thời gian tác dụng dài } \\
\text { (glibenclamid, glimepirid) }\end{array}$ & $\begin{array}{l}\text { Nguy cớ hạ đường } \\
\text { huyết kéo dài }\end{array}$ & 8 & 13,56 \\
\hline 18 & $\begin{array}{c}\text { Thuốc tăng nguy cơ gây ngã: Benzodiazepine } \\
\text { (diazepam) }\end{array}$ & $\begin{array}{c}\text { Giảm chức năng não bộ, Rối } \\
\text { loạn cân bằng }\end{array}$ & 3 & 5,08 \\
\hline 19 & Thuốc tăng nguy cơ gây ngã̃: Thuốc an thần(sulpiride) & Rối loạn phối hợp động tác & 1 & 1,69 \\
\hline 20 & $\begin{array}{l}\text { Thuốc tăng nguy cơ gây ngã: Thuốc an thần gây ngủ } \\
\text { Z-drug (zopiclone) }\end{array}$ & $\begin{array}{c}\text { An thần kéo dài ban ngày, } \\
\text { mất điều hòa }\end{array}$ & 3 & 5,08 \\
\hline 21 & $\begin{array}{c}\text { Amitriptilin với bệnh nhân tăng sản tiền liệt tuyến, } \\
\text { bí tiểu }\end{array}$ & $\begin{array}{l}\text { Nguy cơ nặng them } \\
\text { bệnh lý này }\end{array}$ & 1 & 1,69 \\
\hline \multicolumn{3}{|c|}{ Tống số PIM } & 59 & $\mathbf{1 0 0}$ \\
\hline
\end{tabular}

Nhận xét: Nghiên cứu ghi nhận được 21 loại PIM theo STOPP 2014. Trong đó, PIM hay gặp nhất là Aspirin ở bệnh nhân có tiền sử loét dạ dày tá tràng không dùng kèm PPI $(20,34 \%)$, các sulphonylurea có thời gian tác dụng dài như glibenclamid, glimepirid (13,65\%), PPI điều trị viêm loét dạ dày tá tràng không biến chứng hoặc viêm trợt thực quản khi dùng liều đầy đủ $>8$ tuần $(11,86 \%)$. Các PIM còn lại chỉ gặp 1-3 trường hợp trên đơn thuốc.

\subsection{Các yếu tố ảnh hưởng đến khả năng} gă̆p PIM

Phân tích đơn biến. Sử dụng kiểm định Chi - bình phương (Chi-square) đđể kiểm định mối quan hệ giữa các biến PIM với lần lượt các yếu tố: giới tính, lứa tuổi (do trong nghiên cứu số BN từ 90 tuổi là 3 nên gộp vào nhóm từ 75 tuổi trở lên), đa dược học,các bệnh lý được chẩn đoán cho thấy kê 5 thuốc trở lên trong đớn có nguy cơ tăng khả năng gặp PIM hơn đơn có từ 1-4 thuốc $(\mathrm{OR}=2,733, \mathrm{p}=0,001)$. Bệnh nhân có mắc bệnh hệ tuần hoàn, bệnh hệ tiêu hóa, bệnh hệ sinh dục-tiết niệu có nguy cơ gặp PIMs hơn nhóm bệnh nhân không mắc bệnh $(p<0,05)$.

Phân tích hồi quy đa biến. Sử dụng phương pháp Enter trong phân tích hổi quy logistic được thực hiện để đánh giá mức độ ảnh hưởng của các biến độc lập có khả năng gặp PIMs theo SPSS 2014. Lựa chọn các biến được xác định có mối liên quan độc lập với khả năng gặp PIM theo phân tích đôi biến ở trên bao gồm: bệnh hệ tuần hoàn, bệnh hệ tiêu hóa, bệnh hệ sinh dục-tiết niệu, đa dược học. Kết quả ghi nhận như sau:

Bảng 2. Phân tích hôi quy đa biến các yếu tố ảnh hưởng đến khả năng gặp PIM

\begin{tabular}{|c|c|c|c|c|}
\hline \multicolumn{2}{|l|}{ Thông số } & Di & p-value & OR (95\%CI) \\
\hline \multirow{2}{*}{ Đa dược học } & 1-4 thuốc & & & 1 (tham chiếu) \\
\hline & $\geq 5$ thuốc & 1 & 0,02 & $2,307(1,130-4,711)$ \\
\hline \multirow[t]{2}{*}{ Bệnh Hệ tuần hoàn } & Không & & & 1 (tham chiếu) \\
\hline & Có & 1 & 0,010 & $2,828(1,287-6,215)$ \\
\hline \multirow[t]{2}{*}{ Bệnh hệ tiêu hóa } & Không & & & 1 (tham chiếu) \\
\hline & Có & 1 & 0,005 & $2,694(1,353-5,364)$ \\
\hline \multirow[t]{2}{*}{ Bệnh hệ tiết niệu - sinh dục } & Không & & & 1 (tham chiếu) \\
\hline & Có & 1 & 0,058 & $1,992(0,976-4,067)$ \\
\hline
\end{tabular}


Nhận xét: Các yếu tố làm tăng khả năng gặp PIM theo STOPP 2014 gồm đa dược học $\mathrm{OR}=2,308 \quad(\mathrm{CI} 95 \%=1,130-4,711, \quad \mathrm{p}=0,022)$ ， bệnh hệ tiêu hóa $O R=2,694 \quad(C I 95 \%=1,353$ $5,364, p=0,005)$ và bệnh hệ tuần hoàn $\mathrm{OR}=2,828 \quad(\mathrm{CI} 95 \%=1,287-6,215, \quad \mathrm{p}=0,010)$. Trong đó bệnh hệ tuần hoàn là yếu tố có ảnh hưởng mạnh nhất đến khả năng gặp PIM theo STOPP 2014, nhóm bênh nhân có bênh tuần hoàn có nguy cơ gặp PIM cao gấp 2,8 lần so với nhóm không có bệnh tuần hoàn.

\section{BÀN LUÂN}

Về tỷ lệ PIM trên đơn thuốc theo STOPP 2014. Tỷ lệ PIM phát hiện được trên đơn theo công cụ STOPP dao động ở các nghiên cứu khác nhau tại các quốc gia khác nhau: Ở Mỹ (2016) tỷ lệ này là $40,4 \%$, ở Anh $(34,5 \%)$, ở Irish $(75,7 \%)$, Thụy Sỹ $(77 \%)$, Châu Âu (53,1\%), úc (60\%). Tại Việt Nam có 2 tỉnh thành đã tiến hành đánh giá là Hà Nội $(19,4 \%)$ và Quảng Trị $(16,5 \%)$ [2],[3]. Nghiên cứu của chúng tôi cho kêt quả tỷ lệ kê đơn không phù hợp là 18,85\%.

Vê các loại PIM trên đơn thuốc theo STOPP 2014. Với 80 mục và những đặc trưng khác nhau về thuốc sẵn có, tình trang bệnh lý và tình hình thực tế nghiên cứu thì các loại PIM ghi nhận được trong các nghiên cứu rất đa dạng. PIMs phổ biến nhất được phát hiện theo nghiên cứu của Encarnación (2016) gôm benzodiazepin dùng trên 4 tuần $(38,6 \%)$, tiếp theo là thuốc kéo dài hơn khuyến cáo $(13,6 \%)$ và kê toa trùng lặp $(7,6 \%)$. Nghiên cứu của chúng tôi ghi nhận được 21 loại PIM theo STOPP 2014. Trong đó, PIM hay gặp nhất là Aspirin ở bệnh nhân có tiền sử loét dạ dày tá tràng không dùng kèm PPI $(20,34 \%)$. Tỷ lệ gặp PIM này ở bệnh viện Hữu Nghị là 3,7\%.

Các nghiên cứu cho thây tác dụng không mong muốn thường gặp nhất với aspirin là chảy máu. Khoảng 48/10.000 người uống aspirin hàng ngày trong 10 năm sẽ có chảy máu và $117-182$ người sẽ bị chảy máu tiêu hóa ít nghiêm trọng hơn. Nguy cơ đột quy xuất huyết cũng tăng lên khi sử dụng aspirin cao hơn khoảng 1,84 lần so với statin. Ở người lớn tuổi tăng nguy cơ chảy máu cũng như nguy cơ đau tim và đột quy. Cụ thể nguy cơ nền của các biến cố đường tiêu hóa tăng mạnh từ 1-2/1000/năm năm ở tuổi 60 đến khoảng $7 / 1000 /$ năm ở tuổi trên 80 . Nguy cơ chảy máu tăng dần theo độ tuổi, khi bệnh nhân trên 75 tuổi có nguy cơ mắc bệnh nhân trẻ hơn gấp ba lần (OR 3.10, 95\% CI: 2,27 -4,24; $\mathrm{P}$ $<0,001)$. Và rủi ro chảy máu gây tử vong thậm chí lớn hơn gấp năm lần ( $\mathrm{OR}=5,53$ 95\%CI: 2,65$11,54 ; \mathrm{P}<0,001)$. Do đó, các khuyến cáo lưu ý PPI nên được khuyến cáo để giảm nguy cơ chảy máu đường tiêu hóa trên ở bênh nhân đă̆c biêt ở bệnh nhân trên 75 tuổi. Các thử nghiệm lâm sàng đã chỉ ra rằng PPI được dung nạp tốt và liên quan giảm đáng kể nguy cơ chảy máu tiêu hóa và loét. Các PPI có hiệu quả vượt trội so với kháng $\mathrm{H} 2$ và gây ít tác dụng phụ hơn so với các prostanglandin trị liệu. Sự kết hợp aspirin/PPI đã được đã được chứng minh có hiệu quả trong việc ngắn ngừa bệnh tim mạch và đã cho thấy tác dụng chống ung thư ở bệnh nhân thực quản Barret. Trong nghiên cứu đa số các bệnh nhân được chỉ định famotidin như là liệu pháp dự phòng khi sử dụng aspirin do đó không phù hợp so với tiêu chuẩn của STOPP và các hướng dẫn điều trị [1].

PIM gặp với tần suất cao tiếp theo là PPI điều trị viêm loét dạ dày tá tràng không biến chứng hoặc viêm trợt thực quản khi dùng liều đầy đủ $>$ 8 tuần $(15,69 \%)$. Theo tác giả Nguyển Thị Thanh Hương tỳ lệ này là $26,9 \%$. PPI ức chể mạnh việc bài tiết acid da dày, đặc biệt là vào ban ngày sau một liều buổi sáng hàng ngày. Sự ức chế axit kéo dài và tăng dần trong 3-5 ngày đầu sau khi bắt đầu dùng thuốc. Các nghiên cứu ghi nhận những TDKMM gặp phải khi kéo dài đợt trị liệu PPI bao gồm: Viêm đại tràng do Collagenous, bệnh thận mạn tính, teo dạ dày niêm mạc, thay đổi trong hệ vi sinh đường ruột, bệnh thiếu máu cục bộ não, ung thư dạ dày, ung thư ruột kết, tương tác thuốc. PPI nên được dùng ở liều thấp nhất có hiệu quả và trong thời gian ngắn nhất có thể. Do đó nên tránh dùng lâu dài trên bệnh nhân ngoại trừ trường hợp cần thiết như điều trị duy trì GERD và phòng ngừa sự xuất hiện của loét dạ dày tá tràng trong khi dùng aspirin hoăc NSAID [7].

Một vấn đề đáng lưu ý khi sử dụng thuốc trên người cao tuổi tiếp theo là sử dụng những thuốc tăng nguy cơ gây ngã. Các thương tích phổ biến nhất được thấy sau khi ngã là gãy xương $(59,6 \%)$, chấn thương bề ngoài $(20,9 \%)$ và chấn thương đầu (8,7\%). Một số loại thuốc có liên quan đến nguy cơ bị ngã đáng kể, được gọi là 'thuốc tăng nguy cơ ngã', cơ chế có liên quan đến giảm chức năng vận động, rối loạn cân bằng hoặc rối loạn vận động trên bệnh nhẩn. Woolcott và các đồng nghiệp phân tích, tổng hợp nghiên cứu quan sát đánh giá mối liên hệ giữa ngã và sử dụng thuốc hướng tâm thần, tim và giảm đau ở người già. Cu thể thuốc an thần và thuốc ngủ, thuốc chống trầm cảm và benzodiazepin có mối 
liên quan đáng kể với tỷ lệ ngã khi bệnh nhân dùng thuốc. Theo Landi các benzodiazepin có thời gian bán hủy dài làm tăng nguy cơ ngã (OR=1,45; 95\% (CI) 1,00-2,19]; tương tự như benzodiazepin với thời gian bán hủy ngắn (OR=1,32; KTC 95\% 1,02-1,72). Bên cạnh việc tăng nguy cơ té ngã, việc tiếp xúc với benzodiazepine ở những người già ở cộng đồng có thể gây nên một số hậu quả sức khỏe tiêu cực, bao gồm cả tâm trạng chán nản và mất chức năng thể chất. Bên cạnh đó, tỷ lệ tăng nguy cơ gây ngã của thuốc an thần là 1,47 lần [9].

Ngoài ra trong nghiên cứu cũng ghi nhận các PIM khác với tần suất từ 1-3 lần. Trong đó Glibenclamide như một PIM chính theo STOPP được coi là không phù hợp cho bệnh nhân cao tuổi T2D do nguy cơ hạ đường huyết kéo dài.

Về các yếu tố ảnh hưởng đến khả năng gặp PIM. Với những đặc trưng sinh lý, bệnh lý của người cao tuổi một câu hỏi đặt ra là những yếu tố nào có mối liên quan đến PIM? Các nghiên cứu trên thế giới đều sử dụng mô hình hồi quy logistic và cho những câu trả lời khác nhau.

Tại Mỹ, nguy cơ PIM sẽ là tăng lên $14 \%$ nếu thêm vào đơn một loại thuốc (OR: 1,14, KTC $95 \%=1,06-1,25)$. Sự hiện diện của rối loạn tâm lý (OR: 2,22, KTC $95 \%=1,13-4,37$ ) và mất ngủ (OR: $3,35, \mathrm{KTC} 95 \%=1,80-6,32$ ) là được tìm thấy là những yếu tố dự báo sử dụng PIM. Không có mối liên hệ có ý nghĩa thống kê giữa giới tính hoặc tuổi và PIM [2]. Tại Anh, theo nghiên cứu của Gallagher khi xem xét các yếu tố tuổi, giới tính và số lượng thuốc cho thấy phụ nữ có nhiều khả năng gặp biến cố bất lợi liên quan đến PIM hơn nam giới $(\mathrm{OR}=1,87(95 \% \mathrm{CI}=1,14-$ $3,07), P=0,01$. Bệnh nhân kê đơn dưới 5 thuốc ít có khả năng gặp PIM hơn so với những người được kê đơn từ sáu loại thuốc trở lên $[\mathrm{OR}=0,59$; $95 \%$ CI 0,37-0,96), $p=0,001$ [8]. Nghiên cứu tại 6 bệnh viện châu Âu cho thấy đa dược học (từ 10 trở lên) là một yếu tố nguy cơ gặp PIM (OR: 7,22; 95\% CI: 3,00 - 7,90; p < 0,001)[4],[6]. Tại Việt Nam khi phân tích hồi quy đa biên cho thấy tuổi (với nhóm tuổi từ $75-89$ tuổi: OR $1,44, p=0,003$; nhóm tuổi từ 90 trở lên: $O R$ $2,35, \mathrm{p}=0,047$ ), đa dược học (từ 5 thuốc trở lên: $O R 2,00, p<0,001)$ có liền quan có ý nghĩa thống kê đến khả năng gặp PIM tại BV Hữu Nghị Hà Nội. Kết quả của chúng tôi cũng ghi nhận đa dược học là yếu tố tăng khả năng gặp PIM trên $\mathrm{BN} O R=2,308$ (CI95\%=1,130-4,711, $\mathrm{p}=0,022)$, tuy nhiên tuổi và giới không liên quan đến PIMs.

Ngoài ra, khi xem xét các tình trạng bệnh được chẩn đoán cho thấy $\mathrm{BN}$ mắc bệnh hệ tiêu hóa và bệnh hệ tuần hoàn có nguy cơ cao gặp PIM hơn nhóm bệnh nhân không mắc bệnh với chỉ số nguy cơ lần lượt là $\mathrm{OR}=2,694$ $(\mathrm{CI} 95 \%=1,353-5,364, \mathrm{p}=0,005)$ và $\mathrm{OR}=2,828$ $(\mathrm{CI} 95 \%=1,287-6,215, \mathrm{p}=0,010)$. Đối với $\mathrm{BN}$ có bệnh tuần hoàn, có $132(47,48 \%)$ trường hợp được chỉ định aspirin tuy nhiên rất ít trường hợp được dự phòng nguy cơ xuất huyết tiêu hóa bằng PPI như khuyến cáo mà đa số hoặc không kèm thuốc dự phòng hoặc phối hợp với kháng H2 (famotidine) do đó đây là PIM được ghi nhận nhiều nhất. Đối với BN có bênh tiêu hóa được chỉ định PPI điều trị viêm loét dạ dày tá tràng không biến chứng hoặc viêm trợt thực quản nhưng dùng liều đầy đủ từ hơn 8 tuần trở lên với tỷ lệ 11,86\% nên đây cũng là một PIM chiếm tỷ lệ cao.

\section{KẾT LUẬN}

Nghiên cứu cho thấy có tình trạng kê thuốc có khả năng không thích hợp (PIM) trên đơn thuốc bệnh nhân cao tuổi ngoại trú với tỷ lệ 18,35\%. Cần lưu ý và cân nhắc khi sử dụng các thuốc hay gặp PIM như aspirin ở bệnh nhân có tiền sử loét dạ dày tá tràng, các sulphonylurea có thời gian tác dụng dài như glibenclamid, glimepirid, PPI điều trị viêm loét dạ dày tá tràng không biến chứng hoặc viêm trợt thực quản...

Hạn chế kê nhiều thuốc trên bệnh nhân cao tuổi đặc biệt từ 5 thuốc trở lên do tăng khả năng gặp PIM

Thận trọng và cân nhắc kỹ khi sử dụng thuốc trên bệnh nhân cao tuổi có bệnh lý tim mạch và tiêu hóa do cả bệnh lý tim mạch và bệnh tiêu hóa đều có mối liên hệ tách biệt, độc lập liên quan tới việc tăng khả năng gặp PIM OR lần lượt là $O R=2,694(p=0,005)$ và $O R=2,828(p=0,010)$.

\section{TÀI LIÊU THAM KHẢO}

1. David A. Peura, MD1 C. Mel Wilcox, MD2, Aspirin and Proton Pump Inhibitor Combination Therapy for Prevention of Cardiovascular Disease and Barrett's Esophagus, Postgraduate Medicine Volume 126, 2014 - Issue 1

2. Encarnación Blanco-Reina (2016), Assessing Potentially Inappropriate Prescribing in Community- Dwelling Older Patients Using the Updated Version of STOPP-START Criteria: A comparison of Profiles and Prevalences with Respect to the Original Version, PLOS ONE | December 1, 2016, DOI:10.1371/ journal. pone. 0167586

3. Gallagher $P$, O'Mahony D. (2008), "STOPP (Screening tool of older persons' potentially inappropriate prescriptions): application to acutely ill elderly patients and comparison with Beers' criteria", Age Ageing, 37, 673-679

4. Gallagher $P$, Lang $P$, Cherubini $A$ et al. (2011), "Prevalence of potentially inappropriate prescribing in an acutely ill population of older 
patients admitted to six European hospitals", Eur. J. Clin. Pharmacol., 67, 1175- 1188.

5. Gallagher $P$, Lang $P$, Cherubini $A$ et al. (2011), "Prevalence of potentially inappropriate prescribing in an acutely ill population of older patients admitted to six European hospitals", Eur. J. Clin. Pharmacol., 67, 1175-1188.

6. Hartholt KA, van Beeck EF, Polinder S, van der Velde N, van Lieshout EM, Panneman MJ, van der Cammen TJ, Patka $\mathbf{P}$, Societal consequences of falls in the older population: injuries, healthcare costs, and long-term reduced quality of life. J Trauma. 2011 Sep; 71(3):748-53.)

7. Janice B. Schwartz, M.D., FACC, MAGS, FAHA (2015), Primary Prevention: Do the very elderly require a different approach?, Trends Cardiovasc Med. 2015 Apr; 25(3): 228-239.

8. O'Mahony D, O'Sullivan D, Byrne S, O'Connor MN, Ryan C, Gallagher P. (2015), "STOPP/START criteria for potentially inappropriate prescribing in older people: version 2", Age Ageing. 44(2), 213-218.

\section{ĐẶC ĐIỂM LÂM SÀNG VÀ XQUANG CỦA BỂNH NHÂN THAY LẠI KHỚP HÁNG NHÂN TẠOO}

\section{TÓM TẮT}

Phẫu thuât thay khớp háng ngày càng được thực hiện phổ biến để điều trị các bệnh lý gây tổn thươñ khớp háng. Tuy nhiên có một số trường hợp phẫu thuật thất bại và cần phải thay lại khớp háng nhân tạo. Mục tiêu: Đánh giá đặc điểm lâm sàng và Xquang của bệnh nhân thay lại khớp háng nhân tạo. Đối tượng và phương pháp: Nghiên cứu mô tả cắt ngang trên 50 bệnh nhân bị hỏng khớp háng nhân tạo không do nhiễm trùng và có chi định thay lại khớp háng. Kết quả: Có 41 bệnh nhân đã thay khớp háng toàn phần $(82 \%)$ và 9 bệnh nhân đã thay khớp háng bán phần $(18 \%)(p<0,001)$. Thời gian trung bình giữa 2 lần thay khớp là $75,8 \pm 68,1$ tháng. Thời gian giữa hai lần thay khớp của nhóm khớp có xi măng và không xi măng lần lượt là $121,0 \pm 68,6$ và $37,3 \pm 37,6$ tháng $(p<0,001)$. Nguyên nhân gây thất bai sau phấu thuật thay khớp háng hay gặp lần lượt là lỏng khớp $(72 \%)$, trât khớp (20\%), gãy xương quanh chuôi $(4 \%)$ và gãy chuôi $(4 \%)$. Chức năng khớp háng của tất cả bênh nhân đêu ở mức độ kém. Trên phim chup Xquang $90 \%$ bệnh nhân có hình ảnh tiêu xương đùi và/hoăc ổ cối. Kết luân: Lỏng khớp vô khuẩn là nguyên nhân hay gặp nhất khiến cho bệnh nhân phải thay lai khớp háng nhân taoo.

Tư khoá: thay lại khớp háng

\section{SUMMARY \\ CLINICAL AND RADIOGRAPHIC FEATURES OF PATIENTS WITH REVISION HIP ARTHROPLASTY}

Hip arthroplasty for the treatment of hip joint's diseases has been increasingly performed. However, some are not succesful and have revision. Aim: To evaluate clinical and radiographic features of patients

\section{${ }^{1}$ Bênh viên Viêt Đức \\ 2 Trường Đai hoc Y Hà Nôi}

Chịu trách nhiệm chính: Trân Mạnh Hùng

Email: drhung30@gmail.com

Ngày nhận bài: 17.5.2021

Ngày phản biên khoa hoc: 2.7.2021

Ngày duyệt bài: 19.7.2021

\section{Trần Mạnh Hùng ${ }^{1}$, Nguyễn Xuân Thuỳ ${ }^{2}$}

with revision hip arthroplasty. Patients and method: A cross-sectional descriptive study of 50 patients who were indicated for revision hip replacement due to aseptic hip prosthesis failure. Results: There were 41 patients underwent total hip replacement (82\%) and 9 patients underwent partial hip replacement $(18 \%)$ $(p<0,001)$. The mean time between the last surgery and the next revision surgery was $75,8 \pm 68,1$ months. The time between two hip replacements of cemented and non-cemented hip prosthesis was $121,0 \pm 68,6$ and $37,3 \pm 37,6$ months, respectively $(p<0,001)$. The reasons of failure after hip replacement were aseptic loosening $(72 \%)$, dislocation $(20 \%)$, peri-prosthesis fracture (4\%) and femoral stem fracture (4\%). Hip function of all patients was poor. Radiography showed that $90 \%$ of patients had femoral and/or acetabular bone loss. Conlusion: Aseptic loosening was the most common cause of revision hip replacement.

Keyword: revision hip replacement.

\section{I. ĐĂT VẤN ĐỀ}

Phẫu thuâtt thay khớp háng nhân tạo đã được thực hiện trển thế giới từ cuối thễ kỉ thứ 19 để điểu trị những trường hợp tổn thương khớp háng như gã்y cổ xương đùi do chấn thương, hoại tử chỏm xương đùi, thoái hoá khớp háng, viêm cột sống dính khớp, u xương.... Ước tính tỉ lệ thành công của phẫu thuật đạt trên $90 \%$, giúp hồ chức năng khớp háng và cải thiện chất lượng cuộc sống cho bệnh nhân. Cùng với sự già hoá dân số, số lượng phẫu thuật thay khớp háng nhân tạo ngày càng tăng. Tuy nhiên, khớp háng nhân tạo có tuổi thọ nhất định. Phẫu thuật thay lại khớp háng nhân tạo đã được nhắc đến trong y văn từ những năm 80 của thế kỉ trước [1]. Tỉ lệ thay lại khớp háng nhân tạo khoảng $1 \% /$ năm trong vòng 15 năm đầu [2].

Tại Việt Nam, phẫu thuật thay khớp háng nhân tạo lần đầu được thực hiện vào những năm 70 của thế kỉ trước, nhưng khoảng gần 20 năm nay mới thực sự được phát triển và áp dụng phố 